\title{
MANAGING THE COLD CHAIN: A CASE STUDY AT A SOUTH AFRICAN ICE CREAM COMPANY
}

\author{
J. Grobler ${ }^{1}$ and V.S.S. Yadavalli ${ }^{2}$ \\ ${ }^{1,2}$ Department of Industrial and Systems Engineering \\ University of Pretoria, South Africa \\ ${ }^{1}$ jacomine.grobler@gmail.com, ${ }^{2}$ sarma.yadavalli@up.ac.za
}

\begin{abstract}
This paper documents the results of a supply chain management (SCM) case study conducted at Centurion Ice Cream and Sweets CC, a producer of ice cream in the greater Gauteng area. The current SCM environment was first analyzed before the distribution function was identified as a prime candidate for further analysis. A Monte Carlo simulation was subsequently performed to investigate the effect of different distribution scenarios. The paper concludes with an investigation into information technology (IT) as the enabler for improved supply chain performance.
\end{abstract}

\section{OPSOMMING}

Hierdie artikel dokumenteer die resultate van ' $n$ voorsieningskanaalgevallestudie uitgevoer by Centurion Ice Cream and Sweets CC, ' $n$ roomysvervaardiger in die Gauteng-area. Die voorsieningskanaal is eers ontleed voordat die distribusiefunksie geïdentifiseer is as ' $n$ kandidaat vir verdere analise. ' $n$ Monte Carlo-simulasie uitgevoer om die effek van verskillende distribusiescenarios te ondersoek. Die artikel sluit af met ' $\mathrm{n}$ ondersoek na inligtingstegnologie as katalisator vir verbeterde voorsieningskanaalprestasie.

\footnotetext{
${ }^{1}$ The author was enrolled for an M Eng (Industrial) degree in the Department of Industrial and Systems Engineering, University of Pretoria.
} 


\section{INTRODUCTION AND BACKGROUND}

As early as the Industrial Revolution, managers realized that working closely with other businesses was essential for continued success. Since those early days, effective supply chain management (SCM) has developed into an integral part of any business strategy [1]. The successful implementation of strategies aimed at improving supply chain performance is, however, greatly dependent on the industry as well as on the unique business environment in which a business finds itself.

Centurion Sweets CC, trading as Centurion Ice Cream and Sweets Factory Shop, has established itself as a high quality ice-cream supplier in the Centurion area. The product mix consists of approximately 930 different types of sweets and ice cream products. Nine different product types, available in 13 flavours, are produced inhouse. Meeting the ice cream needs of almost 400 schools in Gauteng, the business generates an annual turnover in excess of R4 million. Klein Kariba, the University of Pretoria, and the South African Police Service are just some of the regular clients.

The production facility is located on 500 square meter premises. Twenty-eight workers are currently employed, and four ice cream machines, four refrigerated one-ton delivery vehicles, and 100 square meters of cold storage are utilized during the day-to-day operation of the factory. The organizational structure of this family business is relatively simple, consisting of owners Charles and Erica Meeser, the production manager, the sales representative, and an employee who is in charge of sales. Two cashiers, three drivers, two assistants, a cleaning lady, nine production workers, and another general assistant are also employed.

The production process consists of a number of simple steps. Firstly, ice cream in liquid form is mixed and 'packaged' into cones. After a 12-hour freezing period, the dipping process can begin. After dipping, the cones are frozen again for a couple of hours before the products are individually packaged in cardboard boxes, ready for distribution.

Since this paper documents the results of a case study conducted at Centurion Ice Cream, the current SCM environment was first analyzed (as discussed in the next section) before the distribution function was identified as a prime candidate for further analysis. A Monte Carlo simulation was then used to investigate the effect of different distribution scenarios. The paper concludes with an investigation into information technology (IT) as enabler for improved supply chain performance.

\section{ANALYSIS OF THE EXISTING SUPPLY CHAIN}

This section discusses the use of the Supply Chain Operations Reference (SCOR) model to analyze the current state of affairs at Centurion Ice Cream. Owing to the important influence of company strategy on supply chain management activities, the company strategy is briefly stated before the actual analysis is done.

\subsection{The business strategy}

Centurion Ice Cream CC attempt to differentiate themselves from their competitors by striving for unsurpassable quality and impeccable customer service. A more 
complete picture of the company strategy can be provided by referring to Kaplan and Norton's balanced score card [2] as drawn up for Centurion Ice Cream.



Figure 1: The strategy map of Centurion Ice Cream [3]

From the strategy map in Figure 1, it is clear that in order to provide excellent customer service and improve market share, greater emphasis needs to be placed on producing high quality products more efficiently. One important way of achieving 
this is through improved supply chain management. Improving the performance of the supply chain requires improved supplier reliability and reduced inventory to ensure that a large variety of products and services can be provided within a short time.

\subsection{The Supply Chain Operations Reference (SCOR) model}

The SCOR model is the first cross-industry framework used for evaluating and improving enterprise-wide supply-chain performance and management [4]. Two key concepts, namely geographic product flow diagrams and the recommended high level (level one) performance measurements, were used to analyze the Centurion Ice Cream supply chain.

\subsubsection{Developing supply chain threads from the geographic product flow}

A geographic product flow diagram is useful in providing an overview of the different activities that take place in a supply chain, as well as the physical location of the supply chain partners. From the geographic product flow diagram in Figure 2, it is clear that most of the immediate suppliers and customers are located around the Gauteng area (South Africa).

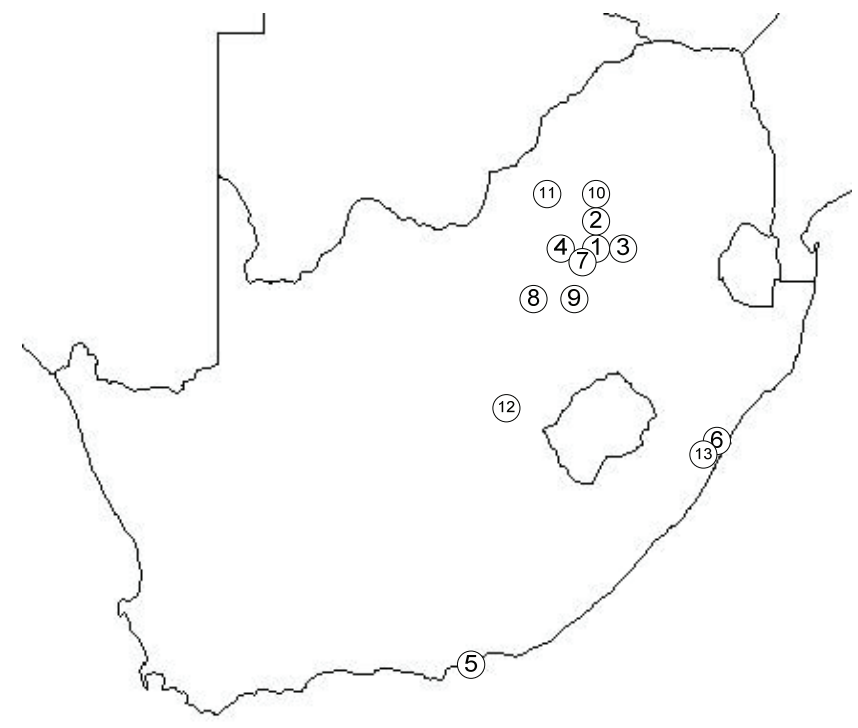

1. Manufacturer (S1, S2, D1, SR1, DR1); 2, 3 and 4. Supplier (D1, DR1); 5 and 6. Supplier (D1, D2, DR1); 7. Warehouse (S1, S2, D1, D2, SR1, DR1); 8 and 9. Warehouse (S1, S2, D1, SR1, DR1); 10 to 13. Customer (S1, SR1)

Figure 2: Geographic product flow diagram 
In terms of the actual activities that take place as part of the plan-source-makedeliver-return process (indicated with P, S, M, D, and DR in SCOR terminology), a number of factors were taken into consideration in the supply chain thread diagram of Figure 3. First, although supply chain planning takes place in each one of the supply chain tiers, a higher overall planning process is in place between Centurion Ice Cream and their immediate customers, as indicated in the diagram. This level of planning is, however, still lacking on the supply side. Second, the demand for ice cream in the South African industry is highly seasonal in nature. This results in most supply chain partners manufacturing on either a make-to-stock or a make-to-order basis, depending on the current inventory levels in the system. Third, although significant effort is made to reduce returns throughout the supply chain, defective product returns still occur.

\subsubsection{Level 1 performance metrics and SCOR performance attributes}

Benchmarking plays a very important role in the successful application of the SCOR process model. With this factor in mind, various performance attributes and level one metrics were defined for Centurion Ice Cream. Table 1 illustrates the measures selected, along with the means of calculation and appropriate targets, while Table 2 links the performance measurements to the SCOR performance attributes. In Table 1 $b_{i j}=1$ if order $i$ of customer $j$ is not filled correctly, $c_{j}=1$ if customer $j$ is not invoiced correctly and $I$ is the total number of order received per month and $J$ is the number of clients serviced. An order is considered to be unfilled if, upon arrival at the customer, any single unit is missing or substituted with another unit of similar value. The total monthly scrap measure compares the predicted number of units to be produced per month to the actual number of units produced per month.

\begin{tabular}{|c|c|c|}
\hline Measurement & Calculation & Target \\
\hline Monthly turnover & $\begin{array}{c}\text { Total sales (obtained from } \\
\text { the point-of-sale (POS) } \\
\text { system) }\end{array}$ & R 700000 \\
\hline Gross profit percentage & $\begin{array}{l}\text { Profit or revenue (obtained } \\
\text { from the POS system) }\end{array}$ & $28-32 \%$ \\
\hline $\begin{array}{l}\text { Number of unfilled orders } \\
\text { per month }\end{array}$ & $=1 \sum_{i=1}^{I} b_{i j}$ & 0 \\
\hline $\begin{array}{l}\text { Number of clients invoiced } \\
\text { incorrectly }\end{array}$ & $\sum$ & 0 \\
\hline $\begin{array}{l}\text { Total monthly scrap } \\
\text { percentage }\end{array}$ & (planned - actual)/planned & $10 \%$ \\
\hline $\begin{array}{l}\text { Number of unhappy clients } \\
\text { per month }\end{array}$ & $\begin{array}{l}\text { Randomly selected client } \\
\text { interviews }\end{array}$ & 10 \\
\hline
\end{tabular}

Table 1: Performance measurements for Centurion Ice Cream 


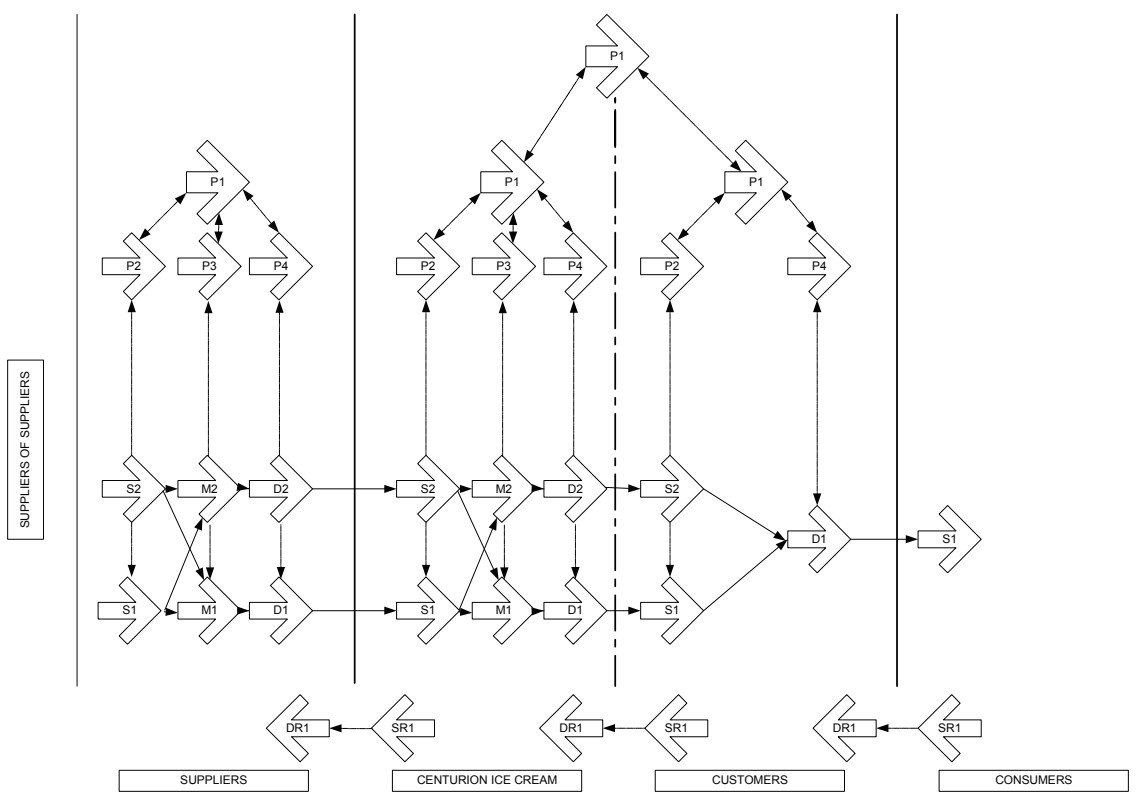

Figure 3: Managing the Centurion Ice Cream supply chain at thread level

\begin{tabular}{|c|c|c|c|c|c|}
\hline \multirow{3}{*}{$\begin{array}{l}\text { First level } \\
\text { metrics }\end{array}$} & \multicolumn{5}{|c|}{ Performance attributes } \\
\hline & \multicolumn{3}{|c|}{ Customer facing } & \multicolumn{2}{|c|}{ Internal facing } \\
\hline & Reliability & $\begin{array}{l}\text { Responsive- } \\
\text { ness }\end{array}$ & $\begin{array}{l}\text { Flexi- } \\
\text { bility }\end{array}$ & Cost & Assets \\
\hline $\begin{array}{l}\text { Number of } \\
\text { unfilled orders } \\
\text { per month }\end{array}$ & YES & & & & \\
\hline $\begin{array}{l}\text { Number of clients } \\
\text { invoiced correctly }\end{array}$ & YES & & & & \\
\hline $\begin{array}{l}\text { Number of } \\
\text { unhappy clients } \\
\text { per month }\end{array}$ & & YES & & & \\
\hline $\begin{array}{l}\text { Downside supply } \\
\text { chain adaptability }\end{array}$ & & & YES & & \\
\hline Monthly turnover & & & & YES & \\
\hline $\begin{array}{l}\text { Gross profit } \\
\text { percentage }\end{array}$ & & & & YES & \\
\hline $\begin{array}{l}\text { Total monthly } \\
\text { scrap percentage }\end{array}$ & & & & & YES \\
\hline
\end{tabular}

Table 2: Level one metrics and performance attributes 


\section{SUPPLY CHAIN NETWORK DESIGN}

This section provides a description of the current supply chain configuration by considering the nature and location of various supply chain partners. It should be noted that this analysis focuses only on the production and distribution of ice cream products, since the other products' supply chain configurations are vastly different.

\subsection{Analyzing the current supply chain configuration}

Understanding the role that each of the supply chain partners play, as well as identifying those partners critical to achieving the strategic objectives of the business, is an important first step in any supply chain optimization or network design initiative. Joubert and Ittman's logistics framework [5], which is provided in Figure 4, can be helpful in this regard, and has been applied to this case study.

First, the primary and secondary issues of concern for Centurion Ice Cream were plotted on Figure 4. From Table 3 it is clear that Centurion Ice Cream management is primarily concerned with the operation of the facilities, distribution function, and operational human resources. Infrastructure supplied to customers and knowledge management with respect to operational human resources and node infrastructure are secondary issues. Second, the various supply chain partners were grouped according to similarity, and each group was plotted on the axes defined in Figure 4. The resulting 'co-ordinates' are indicated in Table 4.

$$
F_{i}=\frac{2\left\|P \cap C_{i}\right\|+\left\|S \cap C_{i}\right\|}{2\|P\|+\|S\|} \quad \forall i \in\{1,2, \ldots, l\}
$$

\begin{tabular}{ll} 
Importance & Vector \\
\hline Primary issues (P) & $\{9,11,12\}$ \\
Secondary issues (S) & $\{5,21,24\}$
\end{tabular}

Table 3: Issues of concern for Centurion Ice Cream

\begin{tabular}{|cc|} 
Partners & Vector \\
\hline Centurion Ice Cream & $\{3,4,5,6,11,12,17,19,20\}$ \\
Clover & $\{1,3,4,7,8,9,11,12,23\}$ \\
Parmalat & $\{1,3,4,9,11,12\}$ \\
Cadbury’s & $\{1,3,4,9,11,12\}$ \\
Beacon & $\{1,3,4,9,11,12\}$ \\
\hline Famous brands & $\{1,3,4,9,11,12\}$ \\
\hline Other smaller suppliers & $\{1,3,4,9,11,12\}$ \\
\hline Agents (Vereeniging and Klerksdorp) & $\{1,3,4,9,11,12,17,20\}$ \\
Schools & $\{4,9,12\}$ \\
Dros & $\{1,4,9,12\}$ \\
\hline Tibbett \& Britten & $\{25,27\}$ \\
\hline Industrial Logistics Systems & $\{1,3,4,9,11,12\}$ \\
\hline Duyn Distribution &
\end{tabular}

Table 4: Categorizing the supply chain partners 
By applying the formula in Equation (1), the intersection of areas of importance with stakeholder involvement can be used to categorize the stakeholders, where $P$ and $S$ respectively denote the primary and secondary vectors of concern, and $C_{i}$ is the vector associated with stakeholder $i$.

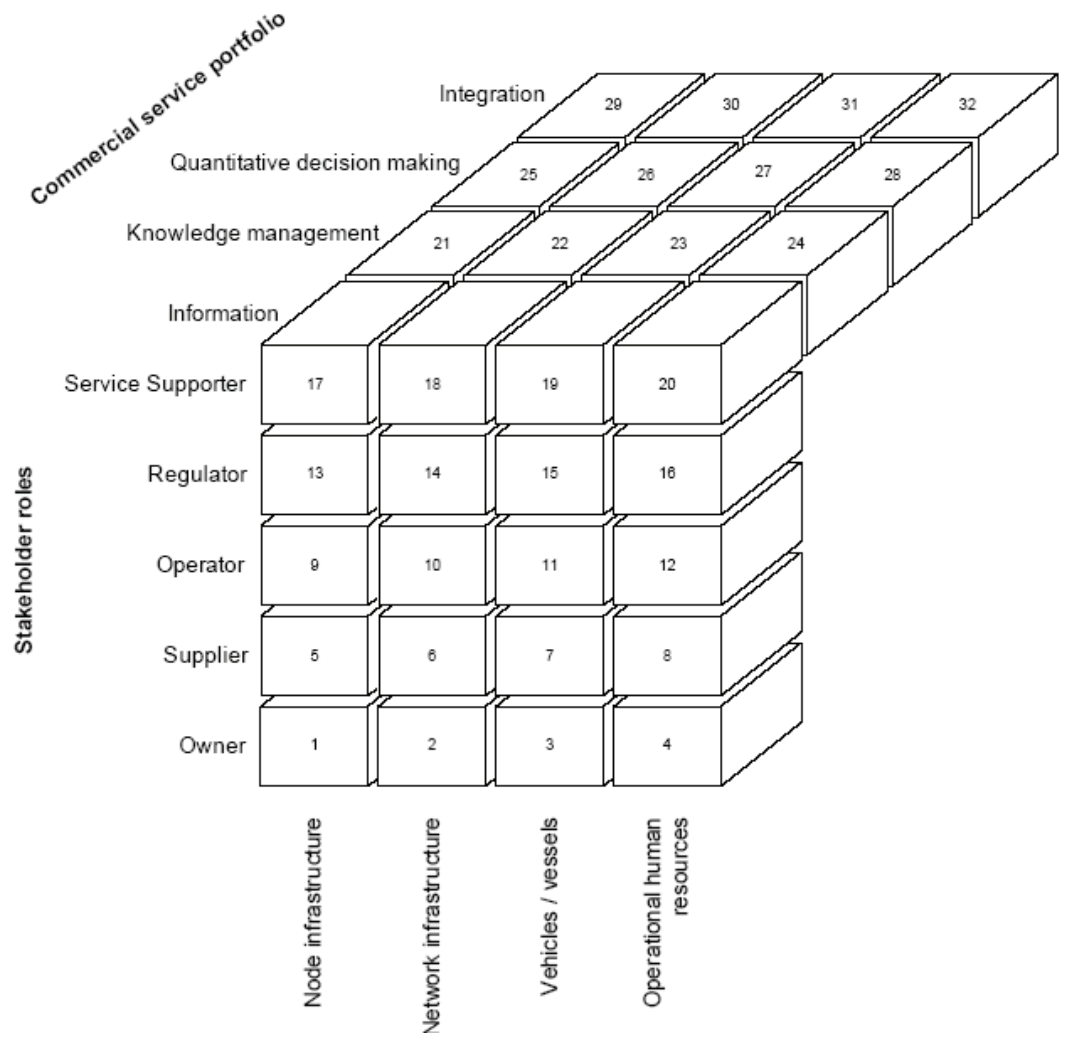

Figure 4: A logistics framework for identifying stakeholders

From Table 5, it is clear that Tibbett \& Britten and Clover are the most important suppliers with whom to negotiate and build relationships. This makes sense on a conceptual level since they are intimately involved with the distribution of frozen goods. Collaboration on a strategic level, where the entire distribution function is outsourced to one of these companies, can also possibly be considered.

From Table 4, it should be clear that Centurion Ice Cream is largely concerned with operational issues. Similar operational issues are, however, currently being addressed by a large percentage of the other partners in the supply chain. Collaboration between Centurion Ice Cream and the smaller suppliers, agents, and 
schools, could result in improved performance of the distribution function. In addition to being a primary issue of concern, the distribution of products to customers lower down in the supply chain presents significant opportunities for improvement. This is an aspect of supply chain management over which Centurion Ice Cream has direct control, and which comprises a large percentage of total monthly cost to company.

\begin{tabular}{|cc|}
\hline Stakeholder & $\mathbf{F}_{\mathbf{i}}$ \\
\hline Tibbett \& Britten & 0.89 \\
\hline Clover & 0.78 \\
\hline Parmalat & 0.67 \\
\hline Cadbury's & 0.67 \\
\hline Beacon & 0.67 \\
\hline Famous brands & 0.67 \\
\hline Other smaller suppliers & 0.67 \\
\hline Agents (Vereeniging and Klerksdorp) & 0.67 \\
\hline Duyn Distribution & 0.67 \\
\hline Dros & 0.44 \\
\hline Schools & 0.44 \\
\hline Industrial Logistics Systems & 0 \\
\hline
\end{tabular}

Table 5: Classifying supply chain partners

The situation is depicted in Figure 5 , which classifies the various supply chain linkages according to the level of involvement identified as necessary for successful supply chain performance. From the network diagram it is clear that there are a number of large corporate suppliers on the supply side, while the demand side consists mostly of schools and other small clients. Since a relatively large amount of activity already exists in the fields of supply chain management and supply chain learning on the demand side, significantly more opportunities for improvement could be identified here.

\subsection{Alternative supply chain strategies}

A number of different aspects can be considered during the design of an alternative supply chain strategy. These range from the location plan of the organization to the fleet size mix. This section addresses each of these aspects first by stating the current situation, and then listing possible alternatives. Those ideas deemed to be feasible are refined and investigated in a later section.

\subsubsection{Location plan}

Centurion Ice Cream currently operates from a single facility located in the Coachmen's Shopping Centre, Hennopspark, Pretoria. A re-evaluation of the current 
location could result in improved operations. Another option includes making use of additional agents or distribution centers. This will in turn involve selecting suitable locations. Furthermore, the use of alternative distribution centers on the supply side as well as fetching raw materials with existing delivery vehicles could also be considered.

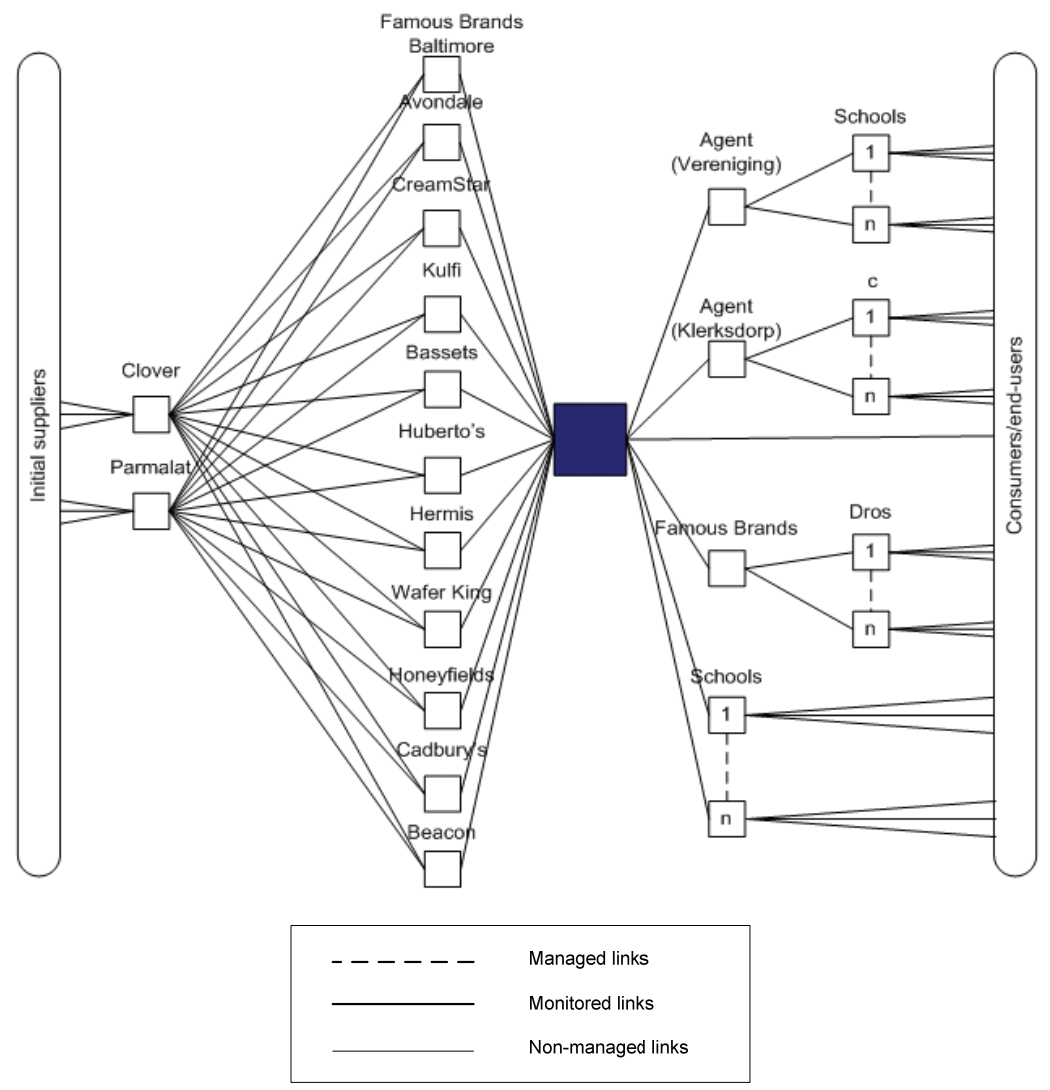

Figure 5: A network diagram of the supply chain [1]

\subsubsection{Product pricing}

Currently all customers are subdivided into delivery territories. Prices vary according to the distance between the delivery territory and the central facility.

Alternatives to consider could be customer-based pricing, transportation-based pricing, or the use of fixed contracts. Customer-based pricing involves billing each 
customer segment individually according to the size and type of order placed. For example, schools can be billed for bulk purchases, while other larger institutions can be serviced and billed on a make-to-order basis. Transportation-based pricing involves billing customers individually according to the distance from the central facility. However, the costs associated with the transactional requirements of such a pricing structure should be considered carefully before a decision is made. Finally, customers can be serviced on a fixed-term contract basis. For a predetermined Rand value, all the ice cream needs of a specific institution can be met by Centurion Ice Cream. Although customer lock-in can be advantageous, this pricing option should be adopted only with great care. However, a number of the existing clientele would appreciate the reduced administrative burden.

\subsubsection{Production management}

Production takes place on both a make-to-order and a make-to-stock basis, depending on the time of year, inventory levels, and type of order. A significant amount of time and effort is spent on smoothing demand by building inventory during the quieter winter months, and making use of overtime and additional machine capacity during peak summer months. Emphasis is also placed on producing the maximum number of units of one flavour before a costly set-up time needs to be incurred. Unfortunately, the demand consists of mostly small quantities of a large number of different flavoured products. This situation may lead to reduced customer satisfaction through incomplete orders being delivered.

Alternative strategies include employing sophisticated production scheduling software, servicing all customers on a make-to-order basis, performing an $A B C$ analysis for customer prioritization purposes, allocating specific machines to different customer segments or flavours, and dedicating specific shifts to specific flavours. Cutting back on product variety as well as focusing on automation and outsourcing are also (possibly less feasible) alternatives.

\subsubsection{Inventory-related aspects}

All inventory is currently stored at the Centurion Ice Cream facility in Pretoria, and raw material orders are placed when needed. Order sizes are kept to a minimum in order to optimize inventory levels throughout the demand side of the supply chain. If it is deemed feasible to make additional facilities operational, significantly more attention will need to be paid to inventory allocation throughout the supply chain.

Alternatives to be considered include reducing the frequency of deliveries by increasing inventory levels at both the production facility of Centurion Ice Cream and the various customer facilities, and working on a re-order point planning basis.

\subsubsection{Vehicle routing, scheduling, and delivery territories}

The distribution function of Centurion Ice Cream is highly dependent on the defined delivery territories, and so these two relatively distinct issues are grouped together in this paper. Depending on their physical location, customers are clustered within seven delivery areas (DAs). Each delivery area is serviced one or more days in a week. Each of the vehicles is assigned to just one delivery area per day. 
Strategies for improvement include improved clustering of customers into delivery territories, using multiple delivery routes per day to service more than one delivery territory, and optimizing the utilization of the trucks. Furthermore, the use of a software-based vehicle routing solution to determine which customers need to be serviced by which vehicles on which days also holds significant opportunities for improvement.

\subsubsection{Carrier set, fleet size mix, and outsourcing}

All products are currently delivered by means of four refrigerated delivery vehicles with equal capacities. Owing to the perishable nature of the product, it is imperative that products are transported in refrigerated vehicles. Different capacities and vehicle types could be the topic of a future analysis.

Outsourcing the distribution function to a third party logistics service provider is another interesting option. The impact on delivery flexibility and the consequences associated with outsourcing a strategic competency should, however, not be ignored.

\subsubsection{Load consolidation}

For all but two of the delivery territories, products are transported directly from the production facility to the customer. The use of additional agents or 'distribution hubs' may be considered.

\subsection{A quantitative assessment of supply chain alternatives}

Although a qualitative analysis of the various supply chain alternatives is valuable in improving understanding of the supply chain, a more quantitative analysis is required to investigate the alternatives that show potential. However, for a quantitative assessment to be meaningful, it is important that the scope and assumptions of the models used portray the actual situation as realistically as possible. Throughout the rest of this section, Monte Carlo simulation is used to evaluate the impact of the various strategies on total distribution cost, customer satisfaction, and working capital.

Owing to the strategic nature of network design and facility location decisions, a total of 816 potential and existing customers were identified. As previously stated, the service area of Centurion Ice Cream currently consists of seven user-defined distribution areas. However, a large degree of uncertainty exists with respect to the number of customer orders received from each of these areas in any given week. To address this issue, the number of customers from each area was sampled from triangular distributions (Table 6) for each of the simulation runs. The actual customers were then randomly selected from the list of potential and current customers in each area.

All models make use of a simplification of Gillett and Miller's sweep algorithm [6] for route construction. Although there are solution techniques that are more suited to obtaining near-optimal routes, this is not the purpose of this paper, and the computational simplicity as well as ease of implementation resulted in this 
algorithm being a suitable choice for incorporation into the Monte Carlo simulation. In a nutshell, all locations are sorted according to their associated polar coordinates, and where allocation of vehicles to routes is also required, the cities are divided up uniformly between the vehicles.

\begin{tabular}{|cccc|}
\hline Distribution area & Minimum & Most likely & Maximum \\
\hline Pretoria (DA 1) & 50 & 90 & 125 \\
\hline Johannesburg (DA 2) & 20 & 36 & 50 \\
\hline Krugersdorp (DA 3) & 10 & 18 & 25 \\
\hline Kempton Park (DA 4) & 20 & 36 & 50 \\
\hline Edenvale (DA 5) & 20 & 36 & 50 \\
\hline Vereeniging (DA 6) & 4 & 8 & 14 \\
\hline Klerksdorp (DA 7) & 4 & 10 & 14 \\
\hline
\end{tabular}

Table 6: The parameters of the triangular distributions from which customers were sampled for each distribution area

Each delivery area is serviced by only one vehicle on a specific day. Thus the size of a delivery area is largely determined by the capacity of the vehicle used. Also, each delivery area is not serviced every day. This is largely determined, however, by the production planning process, and is also a function of the sales and telephone marketing process.

\subsubsection{The current scenario}

Currently, Centurion Ice Cream schedule their distribution function according to Table 7. All customers in Vereeniging (DA 6) and Klerksdorp (DA 7) are serviced by agents. Centurion Ice Cream is only responsible for delivering a relatively large order approximately once a week; all further distribution is the responsibility of the agents. A $15 \%$ cost cut is applied to orders received from agents.

\begin{tabular}{|cccccc|} 
Vehicle & Monday & Tuesday & Wednesday & Thursday & Friday \\
\hline Vehicle 1 & DA 3 & DA 2 & - & DA 2 & DA 1 \\
\hline Vehicle 2 & DA 4 & DA 5 & DA 4 & DA 5 & DA 6 \& \\
\hline Vehicle 3 & DA 1 & DA 1 & DA 1 & DA 1 & DA 1
\end{tabular}

Table 7: The current distribution schedule

\subsubsection{Incorporating minimum order quantities}

Enforcing minimum order quantities (MOQs) should have a significant effect on overall distribution costs. Larger order sizes result in fewer deliveries and greater economies of scale. The downside, unfortunately, is reduced customer satisfaction, since the ordering process becomes less flexile and more inventory needs to be 
maintained on customer premises. This scenario was modeled by adjusting the parameters of the distributions from which the number of orders per week per area are sampled. One sample solution is indicated in Figure 6.

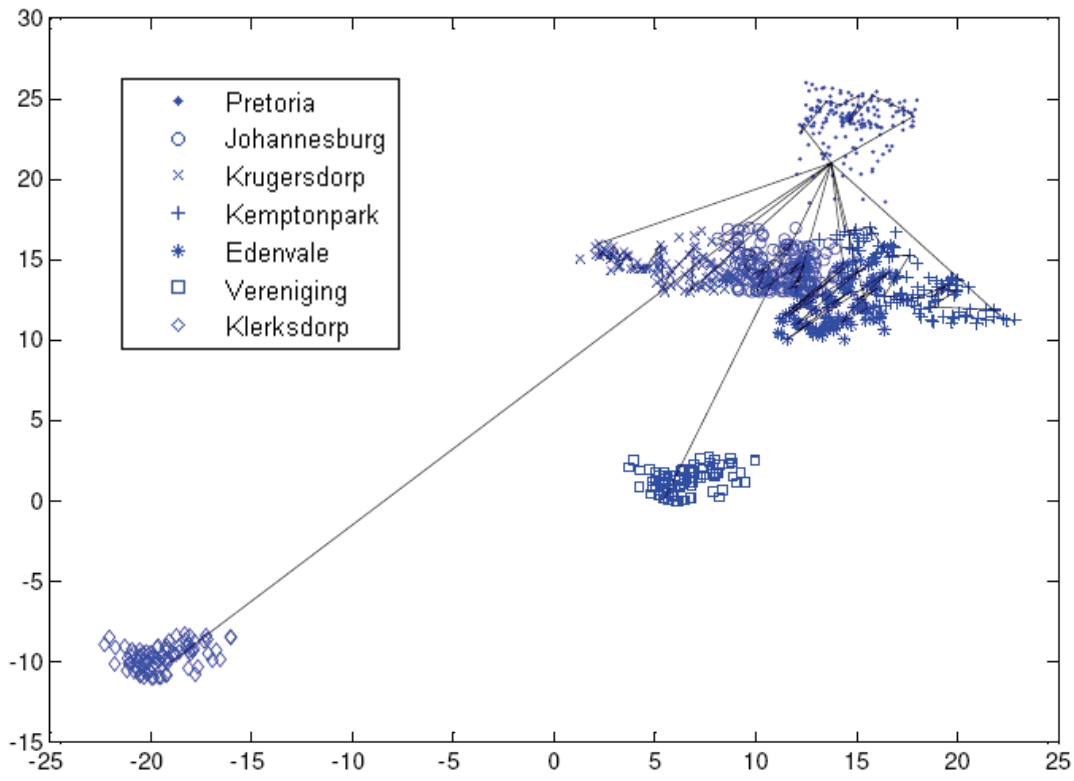

Figure 6: A sample solution with agents

\subsubsection{Removing the agents from the supply chain}

All models make use of a simplification of Gillett and Miller's sweep algorithm [6] for route construction. Although there are solution techniques that are more suited to obtaining near-optimal routes, this is not the purpose of this paper, and the computational simplicity as well as ease of implementation resulted in this algorithm being a suitable choice for incorporation into the Monte Carlo simulation. In a nutshell, all locations are sorted according to their associated polar coordinates, and where allocation of vehicles to routes is also required, the cities are divided up uniformly between the vehicles.

This scenario investigates the impact on total distribution cost if all customers within DA 6 and 7 are serviced directly by Centurion Ice Cream. This involves delivering the various customer orders to individual customer premises, similar to the current state of operations for DAs 1 to 5 . A sample solution is indicated in Figure 7. 


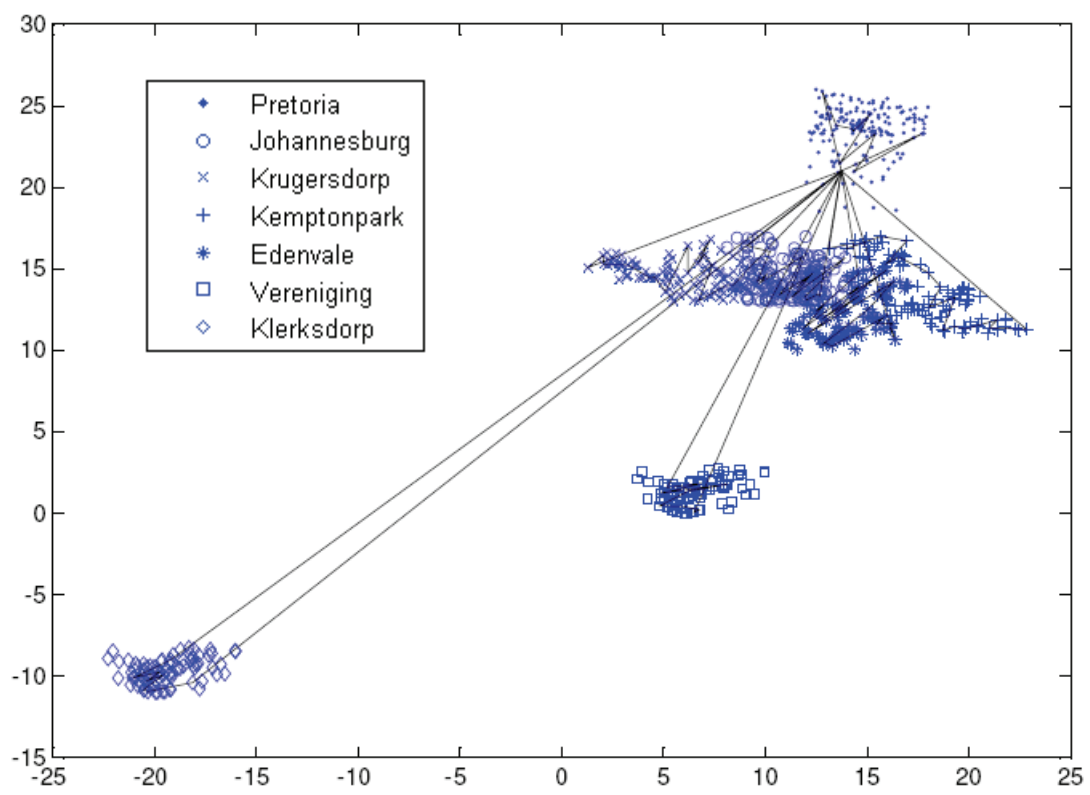

Figure 7: A sample solution with no agents

\subsubsection{Improving customer service in the North West Province}

The last alternative involves opening a second, smaller facility and redistributing the customers according to minimum distance from the servicing facility. The location of this second facility was determined by means of a $k$-means clustering algorithm [7].

The larger 816 data point set was used, and the centroid of the first cluster was kept constant at the location of the Centurion facility. The location of this second facility as well as the two clusters is indicated in Figure 8.

Unfortunately, the redistribution of customers to service facilities had a significant impact on the definition of delivery areas, and the current allocation of customers to areas had to be reconsidered. For each simulation run the sampled customers were allocated to the two facilities. However, in order to address vehicle capacity issues, the two clusters were further subdivided into five delivery areas according to their polar coordinates. These delivery areas are indicated in Table 8.

The assumption is made that the second facility will be completely independent from the central Centurion facility with respect to production and inventory control activities, and that all products distributed from the facility will be produced in- 
house. Since all raw materials are delivered directly to the Centurion facility by suppliers, there will thus be an additional logistics cost (included in the results obtained in Table 9) associated with transporting raw materials and empty containers between the two facilities. Fortunately, the delivery vehicle capacity and product characteristics are such that this trip will only need to be undertaken once a month.

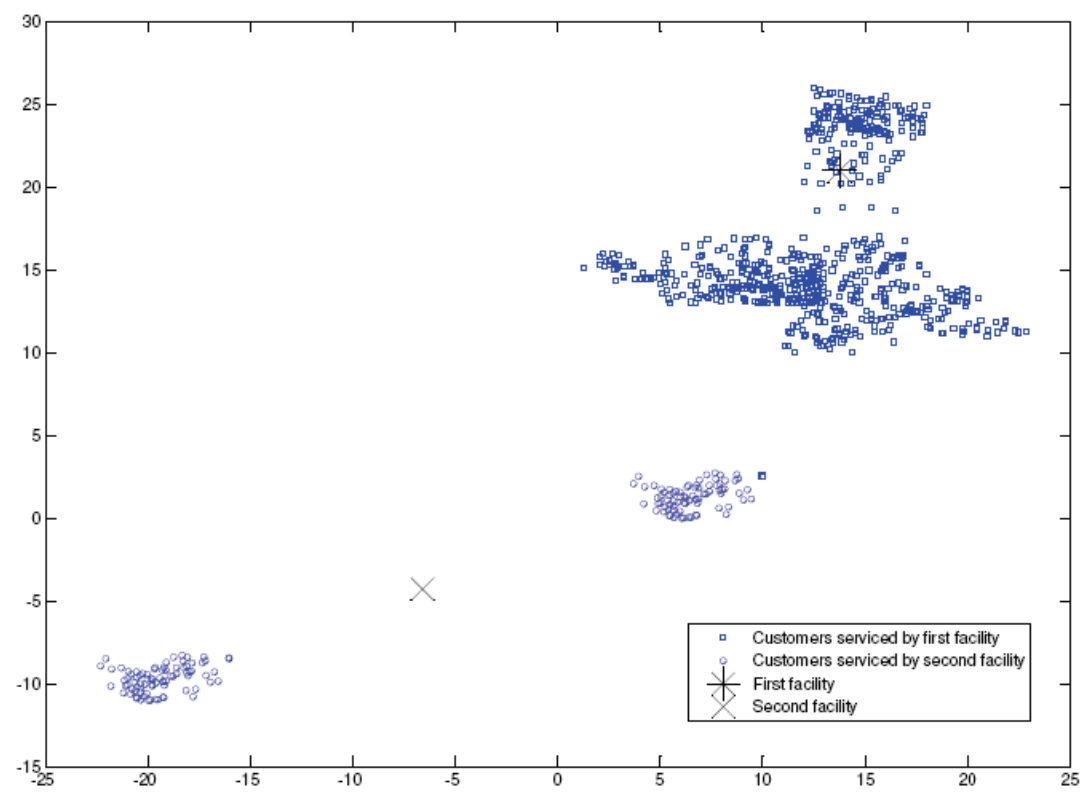

Figure 8: The location of the second smaller facility as determined by a $k$-means clustering algorithm

\begin{tabular}{|cccccc} 
Vehicle & Monday & Tuesday & Wednesday & Thursday & Friday \\
\hline Vehicle 1 & DA 6 & DA 7 & DA 6 & DA 7 & - \\
\hline Vehicle 2 & DA 2 & DA 3 & DA 2 & DA 3 & - \\
\hline Vehicle 3 & DA 1 & DA 1 & DA 1 & DA 1 & DA 1
\end{tabular}

Table 8: The distribution schedule for two facilities

\subsection{Results and recommendations}

Centurion Ice Cream's performance with respect to customer satisfaction and working capital is influenced by a large number of both tangible and intangible 
factors. This resulted in the last two objective functions, namely customer satisfaction and working capital, being defined as a rating on a scale from 1 to 10 , where 10 denotes exceptional performance. Distribution cost is recorded over 30 runs for each simulation.

\begin{tabular}{|ccccc|}
\hline Scenario & \multicolumn{2}{c}{ Total cost } & $\begin{array}{c}\text { Customer } \\
\text { satisfaction }\end{array}$ & $\begin{array}{c}\text { Working } \\
\text { capital }\end{array}$ \\
\hline Current scenario & $\mu$ & $\sigma$ & 5 & 5 \\
\hline No agents & 6027 & 418 & 7 & 5 \\
\hline Agents with MOQ & 6192 & 434 & 3 & 4 \\
\hline No agents with MOQ & 4507 & 245.56 & 5 & 4 \\
\hline Two facilities & 4536 & 272.04 & 8 & 2 \\
\hline Two facilities with MOQ & 14604 & 1689 & 7 & 2 \\
\hline
\end{tabular}

Table 9: The results of the Monte Carlo Simulations

To interpret the results in Table 9, the concept of optimizing multiple objectives simultaneously should be understood. When optimizing more than one objective the aim should be to obtain a set of solutions, referred to as the Pareto Optimal set, which all have the property that no further improvement can be made in one objective function without decreasing the performance in any other objective [8]. The Pareto Optimal set can be analyzed further in conjunction with the decisionmaker, whilst taking into account various other possibly qualitative factors that could not be considered earlier in the optimization process. An analysis of the results in Table 9 results in the Pareto Optimal set being defined as all alternatives apart from the "Two facilities with MOQ" option, which is dominated by the "No agents" alternative.

Further analysis of this Pareto Optimal set could be performed. Establishing a new facility will result in a large amount of capital cost, while MOQ will reduce the business' goodwill. For the time being, the recommendation is to keep the agents as part of the supply chain, but to adjust the cost cut relative to the difference in cost between the current scenario and the "No agents" scenario. The use of MOQ and improved routing should also be investigated further.

\section{INFORMATION TECHNOLOGY AS ENABLER FOR SUPPLY CHAIN SUCCESS}

Information technology (IT) has the potential to play an irreplaceable role in establishing the Centurion Ice Cream supply chain as an industry leader. This section analyzes the existing IT environment, and investigates several opportunities for improvement. 


\subsection{The current IT environment}

\subsubsection{Enterprise Resource Planning (ERP) and Advanced Planning Systems (APS)}

Since the late 1980s the implementation and effective operation of Enterprise Resource Planning systems has become important for the competitive success of many large businesses [9]. However, these systems usually require significant capital investments, and implementation and customization is a costly and time-consuming exercise.

Furthermore, the use of an ERP system is very much dependent on the level of Enterprise Architecture (EA) maturity of the business. Ross et al. [10] define four levels of EA maturity: the Business Silos phase, Standardized Technology phase, Optimized Core phase, and Business Modularity phase. Each phase has its own unique characteristics, and progressing through the four phases is a sequential and gradual process. It is interesting to note that the implementation of an ERP system only occurs at level three, where most of the business processes of the organization have been standardized and all business data is centralized into a single source.

\begin{tabular}{|cc|}
\hline System & Type \\
\hline Accounting system & DOS-based legacy system \\
\hline Inventory management & DOS-based legacy system \\
\hline HR system & Custom-built system \\
\hline Logistics and distribution & MS Office-based system \\
\hline Customer service & 'Telesales' system \\
\hline Forecasting & Manual system \\
\hline Purchasing & Manual system \\
\hline Marketing & Manual system \\
\hline
\end{tabular}

Table 10: Current information systems

Centurion Ice Cream's IT environment can be described as that of a level one organization, where a number of business silos exist around specific functional areas. This translates into a number of independent applications executed on different technology infrastructures, instead of one integrated ERP system.

However, there are some functionalities of an ERP system that are currently being performed by these stand-alone applications. Table 10 lists these 'ERP modules'.

Although an ERP system has the potential to add value to any business, a number of factors need to be addressed at Centurion Ice Cream before this can even be considered. With reference to the above discussion regarding EA maturity, it would be recommended that the business develops a strategy to move into the second phase of maturity. This involves standardizing the technology infrastructure, and could include activities such as integrating all operational information into a single source. 
Opportunities for improvement are also evident in terms of improving the functionality of the various 'ERP modules'. An excellent example is that of improved forecasting being possible with the aid of software-based solutions. This will be discussed in more detail later in this section.

A number of opportunities also exist in terms of advanced planning and optimization. This ranges from more sophisticated techniques used to determine distribution routes and delivery schedules, to the use of supply chain event management (SCEM) principles to improve data and information integration across the supply chain.

\subsubsection{Forecasting}

Forecasting is currently performed manually by the owner. Years of experience result in relatively good 'guesstimates" of demand requirements being available. The use of more formal forecasting techniques could add significant value in this area. Sometimes uncertainty exists with respect to demand patterns, and the sales figure for the corresponding month of the previous year is considered to be the most reliable information available.

Ice cream demand data is highly seasonal, and Centurion Ice Cream has experienced steady growth over the past few years. A formal forecasting technique such as Winter's method [11], which takes both the trend as well as the seasonality of the data into account, should be considered. The final forecast can further be adjusted for environmental factors like weather conditions and drastic changes in market demand, which have a major impact on the accuracy of the forecast results.

It would be recommended that such a custom-designed forecasting system be automated, and that the subsequent application be integrated with the DOS-based inventory and Point of Sale (POS) systems. Furthermore, the accuracy of the forecast can be improved by aggregating the data according to product group or region. A feedback loop should also be incorporated into the demand forecasting process to ensure that actual sales and forecast sales are reconciled, and that any changes that might be required can be made to the system.

\subsubsection{Level of ERP integration}

As was discussed earlier in this section, the IT environment of Centurion Ice Cream consists of a large number of stand-alone applications that perform different functions in the business. This results in a relatively high level of data duplication and reduced data accuracy. Although the ideal scenario would be to progress through the various stages of EA maturity to where a fully functional ERP system is the next step, a short-term solution should be found for the time being.

One such option is the use of middleware, which is discussed in [12]. Processorientated middleware was selected owing to the reduced cost and complexity as well as the focus on managing business data in the form of business processes. Effort should be made to select a commercial-off-the-shelf (COTS) package that adheres to at least $80 \%$ of the business requirements; otherwise expensive customized linkages between the various systems will be required. 


\subsubsection{E-business opportunities}

Although some orders are received via email, the business does not have a website, and the ordering process is completed telephonically with the support of a 'Telesales' system.

Centurion Ice Cream could obtain a significant competitive edge by marketing itself more effectively on the internet. In the future, a website where customers can place orders and view the product mix and services offered by Centurion Ice Cream should be developed. This would be a first step towards more effectively exploiting e-business opportunities.

The benefits of e-business with respect to improved supply chain management are too numerous to mention. For Centurion Ice Cream the creation of a portal for suppliers to interact with the company, as well as for collaboration between other supply chain partners (for example, agents), would probably be the most beneficial. Although a large investment in time and money will be required initially, the effective use of e-business can be instrumental in aiding the business to meet one of its key strategic objectives, namely the expansion of market share in the greater Gauteng area.

\subsubsection{Data accuracy}

Data accuracy was one of the key problems identified by management as critical to address in the near future. An analysis of critical data resulted in a number of internal and external data sources being identified as critical for supply chain success.

The accurate collection and transfer of production data to information which can be used to improve order fulfillment and subsequently customer satisfaction has a major impact on the management of the rest of the supply chain. A manual system is currently in place to record all maintenance and production data on the production floor. Although this data is eventually reconciled with the POS system, the use of an MS Access database could significantly improve the quality and flexibility of the production reports. Work has been done in the past to obtain the specifications for a data warehouse from which queries can be drawn to analyze the production rates per machine per worker per product.

From a supply chain perspective, higher quality supplier and customer data could be helpful in categorizing customers and suppliers according to profitability. Collaboration between partners may also be improved, since the various relationships between Centurion Ice Cream and the other supply chain partners can be monitored more accurately.

APICS [12] lists a number of issues that can be addressed to improve the quality of data in the business. These include defining a suitable data accuracy threshold, capturing the data at the source, and converting to passive data capturing mechanisms. Data is currently captured in batches at the end of a production shift or at the completion of a distribution route by factory personnel. Owing to the relatively stable conditions of the ice-cream industry, this is sufficient, and the high 
costs associated with other real-time capturing mechanisms are not justified. Batch tracking and improved product quality may, however, result from using barcodes on the finished goods, and this option should be investigated in more detail.

\subsection{Inventory management}

Inventory management at Centurion Ice Cream tends to be a reactive process. The POS system is integrated with the company's DOS-based operating system, and the system inventory levels are reconciled with actual inventory levels on a regular basis. However, production planning is done according to available capacity more than actual demand, with the aim of reducing high shortage costs as much as possible. Thus the average inventory levels tend to be relatively high. Unfortunately, the inventory policy has not been $100 \%$ fool-proof over the past few years, since products with smaller demands tend to be out of stock.

This process could be improved by following a re-order point planning process. This will, however, require more accurate inventory data, and the use of barcodes on production pallets and boxes of final products (as discussed in the previous section) should be considered.

Centurion Ice Cream is not currently over-concerned with the appropriate allocation of inventory throughout the supply chain. However, this could also hold significant opportunities for improvement [13]. In Section 3, the use of MOQs was identified as having the potential to reduce logistics costs significantly. An alternative to reducing the cost cuts of agents might then simply be to enforce larger MOQs.

\subsection{Warehouse processes}

In the ice-cream industry the management of storage locations is significant in determining the competitive advantage of a supply chain. Raw material can be categorized into frozen, refrigerated, and non-refrigerated goods. Work-in-progress, as well as final products, are all frozen goods. Owing to the high cost of storage space of frozen goods, it is important to ensure that the use of storage space is optimized. Fortunately, recent expansions have resulted in capacity not being considered a problem.

The various storage locations and associated inventory of the facility are currently being monitored by the factory manager by means of a manual system. The limitations of this system result in inventory levels only being monitored on a relatively aggregated basis. No batch tracking can thus be performed. However, the use of a computerized warehouse management system will not be recommended, since the lack of product complexity does not justify the large initial investment.

\subsection{Future view and recommendations}

In summary, a list of future technologies or IT-based initiatives was compiled and a priority rating between 1 (low impact) and 10 (high impact) was allocated to each initiative to provide an indication of the expected impact of the initiative on overall profitability (Table 11). From the table it is clear that management attention should be given first to designing and maintaining a website, and second to progressing 
towards a level two EA maturity.

\begin{tabular}{|cc|}
\hline Initiative & Priority rating \\
\hline Progress to a level 2 EA maturity & 8 \\
\hline Automate the demand forecasting process & 6 \\
\hline Intelligent vehicle routing and scheduling application & 5 \\
\hline Intelligent production scheduling application & 6 \\
\hline Implement an ERP system & 2 \\
Upgrade IT infrastructure & 7 \\
\hline Design and maintain a web site & 9 \\
\hline
\end{tabular}

\section{Table 11: Evaluation of future IT initiatives}

The simplest and easiest way to improve the use of IT as enabler for supply chain success is for Centurion Ice Cream to appoint an IT specialist on a contract basis for one year. This person should be responsible for the continuous assessment and improvement of the IT infrastructure of Centurion Ice Cream, as well as the management and execution of various IT improvement initiatives as listed in Table 11. The approximate total cost of this position is R120,000 per annum. Although additional hardware costs still need to be factored in, this cost is significantly less than the total cost associated with a major loss in data or infrastructure failure. The implementation of the top two initiatives in Table 11 can thus be considered to be economically feasible.

\section{CONCLUSION}

This paper documented the results of a case study conducted at Centurion Ice Cream. The current SCM environment was analyzed according to the SCOR framework, before the distribution function was identified as a prime candidate for further analysis. A Monte Carlo simulation was subsequently performed to investigate the effect of different distribution scenarios. Finally, the paper investigated Information Technology (IT) as an enabler for improved supply chain performance.

The main recommendations included the use of MOQs, an adjustment in the cost-cut applied to agents, improved routing and scheduling, as well as an improvement through e-business and the development of a centralized data store.

\section{ACKNOWLEDGEMENTS}

The financial assistance of the National Research Foundation towards this research is hereby acknowledged. The opinions expressed in this paper and the conclusions reached are those of the authors, and are not necessarily to be attributed to the National Research Foundation.

Furthermore, the first author wishes to thank Professor A. P. Engelbrecht, Dr. J.W. Joubert, and Susan Alex for their technical assistance during the completion of this 
case study, the anonymous reviewer whose comments helped to improve the quality of this paper, and the University of Pretoria for their continuing financial support.

\section{REFERENCES}

[1] Lambert, D.M. 2006. Supply chain management processes partnerships and performance, $2^{\text {nd }}$ edition, Supply Chain Management Institute.

[2] Kaplan, R.S. and Norton, D.P. 1992. 'The balanced scorecard - measures that drive performance', Harvard Business Review, 70(1), pp. 71-79.

[3] Grobler, J. 2007. 'BIS 780: Final assignment', unpublished paper.

[4] Stewart, G. 1997. 'Supply-chain operations reference model (SCOR): The first cross-industry framework for integrated supply-chain management', Logistics Information Management, 10(2), pp. 62- 67.

[5] Joubert, J.W. and Ittmann, H.W. 2006. 'Framework to scope logistics initiatives', Recent advances in City Logistics, p. 5.

[6] Gillett, B.E. and Miller, L.R. 1974. 'A heuristic algorithm for the vehicledispatch problem', Operations Research, 22(2), pp. 340-349

[7] Omran, G.H., Engelbrecht, A.P. and Salman, A. 2007. 'An overview of clustering methods', Intelligent Data Analysis, 11(6), pp. 583-605.

[8] Rardin, R.L. 1998. Optimization in operations research, Prentice Hall.

[9] Chase, R.B., Aquilano, N.J. and Jacobs, F.R. 2001. Operations management for competitive advantage, McGraw-Hill Irwin.

[10] Ross, J.W., Weill, P. and Robertson, D.C. 2006. Enterprise architecture as strategy: Creating a foundation for business execution, Harvard Business School Press. 